\title{
DIVERSE RESPONSES OF FOREST GROWTH TO DROUGHT TIME-SCALES IN THE NORTHERN HEMISPHERE
}

\author{
Sergio M. Vicente-Serrano ${ }^{1}$, J. Julio Camarero, ${ }^{1,2}$, Cesar Azorin-Molina ${ }^{1}$
}

${ }^{1}$ Instituto Pirenaico de Ecología, Consejo Superior de Investigaciones Científicas (IPE-CSIC), Campus de Aula Dei, P.O. Box 13034, E-50059, Zaragoza, Spain

${ }^{2}$ Dept. d'Ecologia, Fac. Biologia, Universitat de Barcelona. Avda. Diagonal 645, E-08028 Barcelona, Spain.

* Corresponding author: svicen@ipe.csic.es

\section{Biosketchs:}

- Sergio M. Vicente-Serrano is a climatologist focused in the development of methods and tools to improve drought quantification and monitoring, and the analysis of hydrological, agricultural and ecological impacts of drought.

- J. Julio Camarero is a dendroecologist and plant ecologist interested on the analyses of growth and regeneration patterns of woody plants in response to global change.

- César Azorín-Molina is a climatologist interested in the study of extreme weather events and their impacts. He is expert in atmospheric circulation processes from local to regional scales. 


\begin{abstract}
Aim: To identify the main spatio-temporal patterns of tree growth responses to drought time-scales at a hemispheric scale using a climate drought index and tree-ring records, and to determine if those patterns are driven by different climate and forest features.
\end{abstract}

Location: Northern hemisphere.

Methods: We used a large-scale dendrochronological dataset of tree-ring width series from 1657 sites and a time-dependent drought index which incorporates information on precipitation and temperature variability (SPEI, Standardized Precipitation-Evapotranspiration Index). Correlation analysis was used to quantify how tree growth responds to different drought time-scales. The variety in the correlations was summarized by using a Principal Component Analysis (PCA) and the contribution of the various environmental factors was estimated using predictive discriminant analysis (PDA).

Results: The period from the water shortage to the impact on tree growth differs noticeably among forest types and tree families. There is a gradient in the growth responses to droughts including: (i) forests not responding at all to drought such as those located in cold and very humid areas; (ii) forests located in semi-arid areas characterised by responses to long-term droughts; (iii) forests responding to mid-to long-term droughts subjected to sub-humid conditions; and (iv) forests dominating humid sites which respond to short-term droughts.

Main conclusion: Forests located under semi-arid and sub-humid conditions tend to respond to longer time-scales than those located in more humid areas. The characteristic time-scale at which forest growth mainly responds to drought is a proxy of drought vulnerability, reflecting the tree resistance to cope with water deficits of different duration and severity.

Key-words: aridity, climate warming, dendroecology, drought index, forest vulnerability, radial growth, Standardized Precipitation-Evapotranspiration Index. 


\section{Introduction.}

Water availability is one of the main constrains for forest productivity since droughts usually trigger abrupt growth decline (Orwing \& Abrams, 1997), and related die-off and high mortality events (Bigler et al., 2006; Allen et al., 2010; Carnicer et al., 2011). Therefore, analyzing the impact of droughts on tree growth is a priority under the current climatic conditions, in which global warming is probably reinforcing drought severity (Williams et al., 2013). Nevertheless, determining the vulnerability of forests to drought stress is difficult due to: (i) the variety of climate conditions in which forests develop, (ii) the different biomes where forests occur and present contrasting structures, dynamics and compositions, (iii) the different vulnerability of vegetation types to droughts, and (iv) the lack of adequate estimates of drought stress. Among the most widely used drought metrics is the Palmer Drought Severity Index (PDSI) (Palmer, 1965). Nevertheless, this index is unable to portray how droughts change as a function of time scale. The concept of drought time scale (normalized cumulative precipitation or water deficit over the previous $n$ months) is critical in Ecology (Vicente-Serrano et al., 2013). This approach is concerned with the time lag that exists between the onset of water shortage and the identification of its consequences on growth. Thus, diverse growth responses to droughts of different duration and intensity are expected from regional to local scales depending on the climatic conditions of each site and the responsiveness of each tree species (Gutiérrez et al., 2011; Pasho et al., 2011).

Different techniques have been used to determine the response times of vegetation to water deficit and drought (e.g., Craine et al., 2012). A robust approach is to relate multiscalar drought indices with different variables as tree-ring width or vegetation activity measured from satellite imagery (Ji \& Peters, 2003; Pasho et al., 2011). The most widely used drought index calculated on different time-scales is the Standardized Precipitation Index (SPI) (McKee et al., 1993), which is based on precipitation data and recommended by the World Meteorological Organization (Hayes et al., 2011). The different drought time-scales (e.g., 1-month, 2-months, etc.) refer to cumulative 
precipitation available during the period of $n$-months, which is normalized to obtain an index which is comparable in time, space and across time-scales.

Nevertheless, an ecologically relevant drought index must include information of precipitation, but also of air temperature and/or vapor pressure deficit, which also play major roles controlling the evaporative demand of the atmosphere, and affecting tree functioning (Aussenac, 2002; Williams et al., 2013). This is the case of the Standardized Precipitation-Evapotranspiration Index (SPEI) (Vicente-Serrano et al., 2010; Beguería et al., 2014) which successfully allowed detecting the response of vegetation productivity and growth to drought time-scales at a global scale (Vicente-Serrano et al., 2013). The SPEI shows an advantage regarding previous indicators since it combines the sensitivity to the evaporative demand of the atmosphere included in the PDSI with the multi-scalar character of the SPI. Here we aim to identify the main spatio-temporal patterns of treering growth responses to drought time-scales across the Northern Hemisphere using the SPEI, and to determine if these patterns are driven by the biophysical, climatic and ecological conditions that characterize each forest. We fulfill this general objective by taking into account the role of global warming on drought severity, including both precipitation and temperature records in the SPEI calculations.

\section{Material and methods.}

\subsection{Datasets.}

\section{a) Drought index dataset}

The SPEI is based on precipitation and potential evapotranspiration (PET), and it combines the sensitivity of PDSI to changes in evaporative demand with the multiscalar nature of the SPI. Details of the method used to calculate the SPEI can be found in Vicente-Serrano et al. (2010) and Beguería et al. (2014). As an example, we present the evolution of the 2-, 6-, 12- and 24-month SPEI between 1945 and 2006 in the Pratomagno-Bibbiena Appenine mountains (Italy) (Appendix S1 in Supporting Information, Fig. S1). At the shortest time scales (e.g., 3 months) there is a 
continuous alternation of dry (negative SPEI values) and wet (positive SPEI values) periods. At longer time scales (e.g., 12-24 months) droughts are less frequent, but last longer than at shorter scales. Global SPEI data were obtained from the SPEIbase available at http://sac.csic.es/spei/database.html (last accessed 1 February 2014) (Beguería et al., 2010).

\section{b) Tree-ring dataset}

We selected tree-ring data of forests located in the Northern Hemisphere available at the International Tree-Ring Data Bank (ITRDB) (Grissino-Mayer \& Fritts, 1997). This repository contains tree-ring data from over 2000 sites covering the six continents and representing over 100 tree species. These are mainly series of annual tree-ring width data obtained from extratropical forests, mostly located in Northern America and Europe. These series are kindly provided by dendrochronologists and are available online at http://www.ncdc.noaa.gov/paleo/treering.html (last accessed 1 February 2014) We selected the tree-ring width series with at least 25 years of data within the period 1945-2009; a total of 1657 site chronologies were analyzed. The mean length of the samples used for the 1945-2009 period was 40 years. Each local chronology represents the average growth series of several trees (typically more than ten) of the same species growing in the same site. The wood samples are taken and processed following standard protocols and taking two radial cores per tree at $1.3 \mathrm{~m}$ (Stokes and Smiley, 1968).

Tree-ring width measurements were detrended and standardized by the scientists who contributed the chronologies to the ITRDB. Usually, individual series of tree-ring widths are fitted with negative exponential curves or linear functions and residuals are obtained by dividing the observed by the fitted values. The resulting residuals are subjected to an autoregressive modelling and then averaged for each year using a biweight robust mean to obtain a mean chronology of growth indices for each site. Both low- to mid-frequency variability and the first-order autocorrelation are removed to obtain residual or prewhitened tree- width indices. The comparison 
of several detrending types did not alter the main patterns of tree-ring width responses to the SPEI (Appendix S1 in Supporting Information, Fig. S2).

\subsection{Statistical analyses.}

The influence of droughts on tree growth was assessed by using Pearson correlation coefficients computed between the residual site chronologies of tree-ring width indices and the 1- to 24-month SPEI series of the $0.5^{\circ}$ grid that included the corresponding site (see an example in Fig. 1). Therefore, for each tree-ring width series we obtained 288 correlations (12 months x 24 timescales). The 1- to 24-month SPEI series were detrended for the period 1945-2009 before calculating correlations by using a linear regression model fitted to SPEI and time. The average SPEI of each series was added to the residual series of the model.

The high variability in the correlations between the tree-ring growth series and the SPEI series was summarized by calculating a Principal Component Analysis (PCA) (Richman, 1986). This approach allowed classifying the 1657 chronologies on the basis of the similarities of correlations obtained between the tree-ring and the SPEI site chronologies at different time scales. This classification involved calculating a PCA in S mode to identify general patterns in those correlations. Given strong differences in the spatial density of sampling sites among different regions, each tree-ring growth series was weighted by the inverse of the site density calculated within a radius of $300 \mathrm{~km}$. The number of components extracted was chosen based on the percentage of the total explained variance (see Appendix S1 in Supporting Information, Fig. S3). We used a correlation matrix to calculate the PCA (Barry \& Carleton, 2001). The classification was based on the PCA loadings and following the maximum loading rule. The loadings are the correlation coefficients between the pattern of correlation between tree-ring growth and SPEI in each forest and the general pattern representative for a number of forests that correspond to a 
Principal Component (PC). Mapping the loadings allows to identify the forests in which the treering growth response to drought resembles any PC pattern.

To determine the influence of different biophysical (e.g., topography) and climate conditions on the different responses of the tree-ring width chronologies to SPEI time-scales we used several information sources. Firstly, we used data classification for the different forests sampled. Secondly, we focused on the phylogeny (angiosperms vs. gymnosperm species, families) or leaf phenology of each forest species (deciduous vs. evergreen species). Thirdly, we focused on the role played by several climatic variables (i.e., precipitation, mean temperature, potential evapotranspiration -PET, and water balance - precipitation minus PET-, here used as a surrogate of aridity). Climate data was obtained from the CRU TS 3.21 data set (Harris et al., 2013). Fourthly, several geographic and topographic variables (i.e., latitude, elevation, slope, terrain curvature and potential incoming solar radiation inferred from terrain aspect) were also used. Topographic variables were obtained from the GTOPO30 digital terrain model at a spatial resolution of $1 \mathrm{~km}$ (https://lta.cr.usgs.gov/GTOPO30; last accessed 1 February 2014) using the Miramon@ software. Lastly, we also used remote sensing data to estimate forest productivity by means of the average Normalized Difference Vegetation Index (NDVI) (Rouse et al., 1974) obtained from the Global Inventory and (GIMMS) data set (Tucker et al., 2005). This dataset was used to have a measure of the average forest cover at each sampled site between 1981 and 2011, since the NDVI is a parameter closely related to vegetation biomass and leaf area (e.g., Carlson \& Ripley 1997).

We calculated seasonal averages of climate variables and NDVI for each forest. For descriptive purposes, the average values for these variables were obtained for the selected PCA groups that summarized the response of the tree-ring growth to the SPEI time-scales. The contribution of several variables (i.e., climate, topography and NDVI) to explain the spatial differences in the tree-ring growth responses to SPEI at different time-scales was estimated using predictive discriminant analysis (PDA). PDA is used to explain the value of a dependent categorical 
variable based on its relationship to one or more predictors (Huberty, 1994). Given a set of independent variables, PDA attempts to identify linear combinations of those predictors that best separate the groups of cases of the predictand. These combinations are termed discriminant functions (Hair et al., 1998). The PDA allowed assessing which predictors contributed to most of the inter-category differences of the PC modes that summarize the growth-SPEI correlations.

\section{Results.}

\subsection{Spatio-temporal patterns of growth responses to drought.}

Figure 2 shows five examples of the varied growth-SPEI correlations observed at 1- to 24-months temporal scales. For instance, in a cold site from Russia (Ikon river) and a humid site from Canada (Arronsmith Mount) correlations observed between the SPEI and the tree-ring width indices are mainly negative. On the contrary, in a semi-arid site from Mexico (Río Sabinas), positive and high correlations are recorded at intermediate SPEI time-scales (5-6 months). Forests having not so high water deficits show maximum positive correlations at longer SPEI time scales (e.g., Afrascou, 8-10 months and Balsam Gap M. Mitch., 10-12 months).

The varied tree growth responses to the different SPEI time scales were summarized by using a PCA and by analyzing the first seven principal components (PCs). The two first PCs account for $52 \%$ of the variance and they indicate clear patterns of correlation between tree-ring width indices and the SPEI time scales (Fig. 3). The PC1 presents strong growth-SPEI correlations $(\mathrm{r}>0.50)$ at time scales ranging from 10 to 16 months during the boreal spring and early summer (March to July). These forests are defined as showing "long time-scale responses". On the contrary, those forests represented by the PC2 show the highest correlations at SPEI time scales between 3 and 11 months during the boreal summer and early fall (June to September) and they are characterized by presenting "intermediate time-scale responses". Therefore, the patterns of tree-ring growth response to drought time-scales correspond to very different temporal patterns related to the 
seasonality and the drought time-scale, i.e. the period with the most pronounced cumulative water deficit, in which drought drives growth. The PC3 represents $10.9 \%$ of variance and shows strong negative and positive correlations between the tree-ring indices and the SPEI at short time scales (35 months) in winter and summer, respectively. These forests may be classified as sites showing "short time-scale response". The fourth to seventh PCs show more complex growth responses to drought, and they represent less than $10 \%$ of the total variance corresponding to more local patterns than the first three PCs (see Appendix S1 in Supporting Information, Fig. S4). We retained the first three PCs for further analyses because of their more coherent and representative patterns.

The geographical pattern in the distribution of the sites showing long time-scale response to drought (PC1) corresponds mainly to forests located in western and south western North America, but it also includes some forests from the eastern USA and Alaska, the central Iberian Peninsula and eastern Russian forests (Fig. 4). The forests presenting intermediate time-scale response to drought (PC2) correspond to forests located in central and south western North America and also in Central Europe. The northernmost boreal forests from Siberia tend to show negative correlations between the annual tree-ring width indices and the summer SPEI. Overall, the geographical patterns of the forests of long (PC1) and intermediate (PC2) time-scale responses represent different regions.

The maximum loading rule allowed classifying the different forests according to the growth responses to different SPEI time-scales. Forests with long time-scale responses to drought represent $45 \%$ of the analyzed sites, but $37 \%$ correspond to a positive response of growth to drought (positive loadings) whereas the remaining $7 \%$ of those forest show a negative response to drought (i.e., negative loadings representing negative correlations between the tree-ring width indices and the spring-sumer SPEI values at 10-16 months long time scales). This means that we obtained two differentiated groups of forests based on PC1 and characterized either by positive (+) or by negative (-) responses to drought. After applying the same procedure to the other extracted components we found that sites with intermediate (PC2) and short (PC3) time-scale responses to drought represent 
$30 \%$ (18\% and $11 \%$ for positive and negative loadings, respectively) and $13 \%$ (9\% positive and $4 \%$ negative loadings, in that order) of studied forests, respectively.

\subsection{Factors driving growth responses to drought}

The ITRDB dataset is clearly biased towards gymnosperms (83\%) and evergreen tree species (75\%), while angiosperms (17\%) and broadleaf (usually deciduous) tree species are less abundant (25\%). Nevertheless, this distribution differs from the classification obtained from the PCA (Table 1). For instance, the forests with a positive and short time-scale response to drought (PC3+) and the three groups with a negative response to drought show a higher representation of gymnosperms (>90\%) as compared to the total of forests. On the contrary, the forests characterized by long and intermediate time-scale responses to drought $(\mathrm{PC} 1+)$ show a higher frequency of angiosperms (18\%) than the rest of forests. This is even more evident for the forests with intermediate time-scale response to drought (PC2+), which includes many forests dominated by angiosperm (30\%) and deciduous species $(37 \%)$ despite most of the tree species sampled by dendrochronologists are evergreen $(75 \%)$.

The tree family most intensively sampled by dendrochronologists are the Pinaceae, corresponding to the $73 \%$ of the analysed forests (see Appendix S1 in Supporting Information, Table S1). The forests of short time-scale responses to drought (PC3+), and those with a negative response to drought (PC1- and PC2-) show a high percentage of Pinaceae species (at least 76\%), whereas forests of long time-scale responses (PC1+) show a ratio similar to that observed for all total forests. On the contrary, only $57 \%$ of the forests with intermediate time-scale responses to drought $(\mathrm{PC} 2+)$ are dominated by Pinaceae tree species, which means that this group was dominated by families of deciduous angiosperm tree species belonging to Fagaceae (25\%) or by other gymnosperm families such as the Taxodiaceae (7\%). Thus, the PC2+ included tree species from humid, warm or mesic sites such as Quercus stellata or Taxodium distichum (see Appendix S1 
in Supporting Information, Table S2). In addition forests with negative responses to drought (PCs with negative loadings) show higher percentages of Cupressaceae species than the total of forests, corresponding to species dominant in arid or cold areas.

The forests presenting negative responses to drought are located in colder and more humid conditions (i.e., areas with higher precipitation, lower temperature and PET, and more positive water balance) than the forests showing positive responses to drought (Fig. 5). Thus, forests characterized by negative correlations between growth and drought are probably more constrained by radiation and temperature since they are mostly boreal forests. In the case of forests corresponding to positive responses to drought, the forests of long time-scale responses to drought $(\mathrm{PC} 1+)$ usually correspond to drier areas (they present the lowest water balance) than those represented by forests of intermediate time-scale responses. The forests of long time-scale response to drought $(\mathrm{PC} 1+)$ also show a lower annual NDVI and are located at higher elevation than forests of intermediate and short time-scale responses, while forests of intermediate time-scale response present the maximum mean values of temperature and PET. Therefore, the forests with intermediate time-scale response are located in areas characterized by lower climatic stress than forests of long time-scale response. The forests of short time-scale responses display a growth response to drought during the boreal summer. They are located in areas with precipitation values similar to those represented by the forests of intermediate time-scale responses but under colder conditions (lower PET), which determine a higher water balance than those forests of long and intermediate timescale responses to drought. This translates into higher aboveground biomass for forests presenting short time-scale responses, as evidenced by higher annual NDVI values. There appears to be a gradient in the growth responses to drought including: (i) forests not responding at all to drought (e.g., those located in cold and very humid areas corresponding to groups included in the first three PCs with negative loadings); (ii) forests characterized by a growth response to long-term droughts (located in drier areas and showing low NDVI values); (iii) forests characterized by responding to 
mid-term droughts and subjected to humid conditions and showing high NDVI values ; and (iv) finally, those forests growing under more humid conditions, which display higher NDVI values and respond to short-term droughts with lower intensity than forests from other groups (e.g., PC1+ and $\mathrm{PC} 2+)$.

The PDA allowed quantifying the relative importance of the various climatic and environmental factors as drivers of the growth responses to drought (Table 2). The first PDA function (PDA1) accounts for $38 \%$ of the total variance and allows separating between the six patterns (PC1+, PC2+, PC3+, PC1-, PC2-, PC3-) of forest growth response to different drought time-scales. This function represents mainly the latitude, temperature and PET conditions at each forest, showing the different seasonal and annual values of those two climate variables negative and significant coefficients with PDA1. The PDA2 (18\% of variance) shows positive coefficients for summer season temperature and PET. The PDA3 (14\% of variance) displays positive coefficients with precipitation and water balance during the main period of forest activity (from spring to autumn). These three functions emphasize the importance of the average climate conditions (temperature and PET, which are largely determined by latitude, and the water availability during the period of vegetative activity) to discriminate the different patterns of forest response to drought.

The PDA1 discriminates between forests with positive and negative responses to drought (Fig. 6). It means that differences between positive and negative responses are mainly controlled by latitudinal gradients, which are ultimately determining temperature and PET. Thus, the three forest groups characterized by a negative response to drought and the forests showing short time-scale responses to drought $(\mathrm{PC} 3+)$ show positive coefficients in PDA1, whereas forests presenting long $(\mathrm{PC} 1+)$ and intermediate $(\mathrm{PC} 2+)$ time-scale responses to drought show negative coefficients. Nevertheless, the forests characterized by intermediate time-scale response (PC2+) show higher values in the PDA1 than those forests having long time-scale response (PC1+). This means that spatial gradients of temperature and PET do not only determine the positive and negative response 
to drought but whether the response is recorded at intermediate or long drought time-scales in forests that respond positively to drought. The PDA2 also discriminates between forests with positive and negative response to drought, but it also differentiates between the forests with long $(\mathrm{PC} 1+)$ and short $(\mathrm{PC} 3+)$ time-scale responses and the forests with intermediate time-scale responses $(\mathrm{PC} 2+)$. Summer temperature affects evaporative demand in the period of higher water stress by trees. Since water availability during summer in forests of long, intermediate and short time-scale responses differ, the water demand conditions, determined by PET, may affect the response of growth to drought time-scale. This is suggested by PDA3, which represents summer water availability and clearly separates between forests of intermediate (PC2+, more humid) and long (PC1+, drier) time-scale responses to drought.

\section{Discussion and conclusions.}

The diversity of environmental conditions evaluated here allowed detecting a gradient in forest growth responses to drought. We detected that some forests from cold and humid areas respond to shorter drought time scales than forests from dry areas, which usually respond to longer time scales. We also found forests that do not respond to drought variability such as those located in cold and humid regions, here represented by negative response to drought (negative loadings in the first three PCs). On the other extreme, forests characterized by growth responses to long drought time-scales (12-14 months) are located in semi-arid sites and show lower cover and biomass (NDVI) than other forests. Other forests present growth responses to mid-term droughts (6-8 months) and they dominate humid locations where they accumulate high biomass values. Finally, forests in cold and humid sites tend to respond to very short drought time-scales (3-5 months). The patterns of forest response to drought are therefore highly complex even at local scales and among coexisting species or even specific individuals. In this sense, growth and responses to drought are modulated by site 
conditions such as soil type, specific functional traits and competition intensity among neighboring trees (Orwig \& Abrams, 1997, McDowell et al., 2008, Linares et al., 2010, Pasho et al., 2011).

We were able to separate contrasting families based on their responses to drought such as the Pinaceae, Cupressaceae and Fagaceaeae. This classification agrees well with the vulnerability to drought of the compared species since an increased resistance to cavitation is a key mechanism of drought tolerance in conifers and evergreen angiosperms, while in deciduous angiosperms hydraulic conductivity increased with decreasing rainfall (Maherali et al., 2004). Most tree species operate close to their safety margins for hydraulic failure, making them vulnerable to warming-induced droughts across biomes (Choat et al., 2012). To simplify, the wide vessels of angiosperms allow them to reach much higher hydraulic than gymnosperms, whereas gymnosperms maintain much greater safety margins to prevent xylem embolism (Johnson et al., 2012). Our findings evidence that the patterns of growth response to drought do not follow a general geographic structure and that these patterns are driven by the biogeographic, topographic and climate conditions of each site, showing that forests located in different continents have the same pattern of response to drought time-scales. In fact, several of the different analyzed drivers are related (e.g., topography affects temperature and precipitation, the water balance determines the NDVI, etc.), but we found coherent relationships between the analyzed variables and the growth response to SPEI time-scales in agreement with the different climate factors limiting primary production at a global scale (Nemani et al., 2003).

The forests located in cold and wet regions show low PET rates and in general high precipitation values and positive water balances. These forests are not frequently affected by water deficit since growing season temperature is the main constraint of growth (Briffa et al., 1998). Nevertheless, temperature and growth trends may be diverging during the last decades in some boreal forests (Briffa et al., 1998). In fact, some authors suggested that warming-related drought could cause this recent divergence between temperature and growth at high northern latitudes 
(Barber et al., 2000; Wu et al., 2012). This would explain that these forests (represented by negative loadings in the first three PCs) show negative correlations with the SPEI since higher precipitation corresponds to cloudiness, lower solar radiation and, in general, lower temperature, which is the major constrain of tree growth in these areas. On the other hand, a warming-induced rising PET could constrain growth by increasing soil water losses but it could also enhance respiration and carbohydrate consumption (Barber et al., 2000). Nevertheless, these forests may respond to water shortage if drought becomes more severe than it was during the observed record, which is suggested by pre-instrumental tree-ring records and recent high-mortality episodes (Payette \& Delwaide, 2004; Peng et al., 2011).

The forests presenting short time-scale responses to drought are characterized by lower water availability than those forests showing a negative response to drought but by colder and more humid conditions than forests having intermediate and long time-scale responses to drought, mainly as a consequence of low PET rates. Leaf biomass and NDVI values tend to be high in forests with short time-scale responses to drought and, although the response to SPEI variability is lower than that found for forests of intermediate and long time-scale responses, the former forests are responding mainly to drought at short time-scales in the season of higher vegetation activity, i.e. during summer. This behavior is probably suggesting a high vulnerability of these forests to water deficit since although water availability is commonly sufficient in these forests, it is lower than that observed in the forests from the coldest sites. Thus, forests that show a short time-scale response to drought are probably affected by periods of summer water stress, which are increasing in frequency and severity as a consequence of global warming (Dai, 2011; Trenberth et al., 2014). Since forests located in humid regions commonly show a low acclimatization to water-deficit conditions (Maherali et al., 2004), even short drought episodes, here illustrated by short SPEI time-scales, are probably affecting forest growth (Wu et al., 2012). 
The main pattern of growth response to drought, represented by forests of intermediate and long time-scale responses to drought, clearly presented a stronger response to drought than that observed for the other identified patterns. These forests are characterized by lower water availability and higher air temperature than the rest of sites. This is consistent with the fact that tree growth in arid sites is more sensitive to drought than in humid areas (Orwing \& Abrams, 1997; Pasho et al., 2011). Therefore, drought variability is determining a high percentage of the temporal variability of the annual growth of the forests located in xeric sites under semi-arid conditions. In xeric sites the growth response to drought is mainly recorded in summer, given that this season is characterized by higher vegetation activity, water demand and dryness. Nevertheless, the differences found between forests with intermediate and long time-scale responses to drought allow confirming a preliminary finding pointed out by Vicente-Serrano et al. (2013) using different vegetation metrics, namely that the forests located under semi-arid and sub-humid conditions tend to respond to longer time-scales than those located in more humid sites characterized by higher vegetation biomass and NDVI values.

The different responses to drought observed in semi-arid and sub-humid forests is directly linked to their contrasting vulnerabilities to water shortage, being therefore necessary to discriminate between response and resistance or vulnerability. In general, tree species that are able to regulate their metabolism to make a more efficient use of water resources usually show a higher resistance to the drought severity (Abrams et al., 1990). According to a global compilation of the xylem resistance to drought-induced embolism, the vulnerability of tree species from humid forests to water shortage is higher than that observed in tree species from dry forests (Maherali et al., 2004), probably as a consequence of physiological or morphological acclimatization of species from dry forests to cope with recurrent water deficits. This is in agreement with studies analyzing the spatial distribution of tree species across these areas (Pockman \& Sperry 2000, Kursar et al., 2009). Here, we have shown that the drought time-scale at which forest growth is responding to 
drought may be used as a proxy of drought vulnerability, possibly being more related to the resistance to cope with water deficits of different duration and severity than to the vulnerability to xylem embolism. Therefore, the forests that respond to short drought time-scales, characteristics of humid and cold environments, would have a higher vulnerability to the water deficits since their growth is mainly constrained by short-term droughts. On the contrary, the forests located in drier environments respond to long-term droughts, which means that they may cope with short-term water deficits but longer and more severe water deficit episodes must occur to affect their radial growth. This suggests that tree species require different time periods to recover (resilience) after water conditions return to average values in dry environments (Granda et al., 2013) and even in humid temperate forests (Cavin et al., 2013). Therefore, the findings of this study not only support the different growth responses to drought in forests located under contrasting environmental conditions, but they stress the importance of considering different drought time-scales for better understanding how forests respond to drought under different climatic and environmental conditions. If the severity, geographical extent and frequency of droughts increase as a consequence of climate warming as suggested by different studies (Dai, 2013; Trenberth et al., 2014), novel growth responses to drought could be recorded in areas not previously detected (e.g., boreal forests). We should also assess up to which point forests from semi-arid or dry areas will keep their tolerance to water deficit by keeping their characteristic long-term growth responses to drought since novel or extreme climate conditions can profoundly alter these responses and trigger growth decline and related die-off even in areas without pronounced water shortage once these tolerance thresholds are surpassed. Thus, future warming scenarios suggest increased forest vulnerability to drought stress (Williams et al., 2013).

\section{Acknowledgements}


We thank all contributors and also the NOAA (ITRDB), CRU and the Spanish Meteorological State Agency (AEMET) for providing the databases used in this study. This work has been supported by research projects CGL2011-27574-CO2-02, CGL2011-27536 and CGL2011-26654 financed by the Spanish Commission of Science and Technology and FEDER, projects 012/2008 and 387/2011 financed by Organismo Autónomo Parques Nacionales (Spain), project "Demonstration and validation of innovative methodology for regional climate change adaptation in the Mediterranean area (LIFE MEDACC)" financed by the LIFE programme of the European Commission and Project CTTP1/12 financed by “Comunidad de Trabajo de los Pirineos". Third author was supported by the JCI-2011-10263 grant. The authors wish to acknowledge the editor and three anonymous reviewers for their detailed and helpful comments to the original manuscript. 


\section{References}

Abrams, M.D., Schultz, J.C. \& Kleiner, K.W. (1990) Ecophysiological responses in mesic versus xeric hardwood species to an early-season drought in central Pennsyvania. Forest Science, 36, 970-981.

Allen, C.D., Macalady, A.K., Chenchouni, H., Bachelet, D., McDowell, N., Vennetier, M., Kitzberger, T., Rigling, A., Breshears, D.D., Hogg, E.H., Gonzalez, P., Fensham, R., Zhang, Z., Castro, J., Demidova, N., Lim, J.H., Allard, G., Running, S.W., Semerci, A. \& Cobb, N. (2010) A global overview of drought and heat-induced tree mortality reveals emerging climate change risks for forests. Forest Ecology and Management, 259, 660684.

Aussenac, G. (2002). Ecology and ecophysiology of circum-Mediterranean firs in the context of climate change. Annals of Forest Sciences, 59, 823-832.

Barber, V.A., Juday, G.P. \& Finney, B.P. (2000) Reduced growth of Alaskan white spruce in the twentieth century from temperature-induced drought stress. Nature, 405, 668-673.

Barry, R.G. \& Carleton, A.M. (2001). Synoptic and Dynamic Climatology. Routledge, London.

Beguería, S., Vicente-Serrano, S.M. \& Angulo, M. (2010) A multi-scalar global drought data set: the SPEIbase: A new gridded product for the analysis of drought variability and impacts. Bulletin of the American Meteorological Society, 91, 1351-1354.

Beguería, S., Vicente-Serrano, S.M., Reig, F. \& Latorre, B. (2014) Standardized Precipitation Evapotranspiration Index (SPEI) revisited: parameter fitting, evapotranspiration models, kernel weighting, tools, datasets and drought monitoring. International Journal of Climatology, DOI: 10.1002/joc.3887.

Bigler, C., Bräker, O., Bugmann, H., Dobbertin, M. \& Rigling, A. (2006) Drought as an inciting mortality factor in Scots pine stands of the Valais, Switzerland. Ecosystems, 9, 330-343. 
Briffa, K.R., Schweingruber, F.H., Jones, P.D., Osborn, T.J., Shiyatov, S.G. \& Vaganov, E.A. (1998) Reduced sensitivity of recent tree-growth to temperature at high northern latitudes. Nature, 391, 678-682.

Cavin, L., Mountford, E.P., Peterken, G.F. \& Jump, A.S. (2013) Extreme drought alters competitive dominance within and between tree species in a mixed forest stand. Functional Ecology, doi: $10.1111 / 1365-2435.12126$

Carnicer, J., Coll, M., Ninyerola, M., Pons, X., Sánchez, G. \& Peñuelas, J. (2011) Widespread crown condition decline, food web disruption, and amplified tree mortality with increased climate change-type drought. Proceedings of the National Academy of Sciences of the United States of America, 108, 1474-1478.

Carlson, T.N. \& Ripley, D.A. (1997) On the relation between NDVI, fractional vegetation cover, and leaf area index. Remote Sensing of Environment, 62, 241-252.

Choat, B., Jansen, S., Brodribb, T.J., Cochard, H., Delzon, S., Bhaskar, R., Bucci, S.J., Feild, T.S., Gleason, S.M., Hacke, U.G., Jacobsen, A.L., Lens, F., Maherali, H., Martínez-Vilalta, J., Mayr, S., Mencuccini, M., Mitchell, P.J., Nardini, A., Pittermann, J., Pratt, R.B., Sperry, J.S., Westoby, M., Wright, I.J. \& Zanne, A.E. (2012) Global convergence in the vulnerability of forests to drought. Nature, 491,752-755.

Cook, E.R. \& Krusic, P.J. (2005) Program Arstan, a tree-ring standardization program based on detrending and autoregressive time series modeling, with interactive graphics. Tree-ring Laboratory Lamont Doherty Earth Observatory of Columbia University, Palisades, NY.

Craine, J.M., Nippert, J.B., Elmore, A.J., Skibbe, A.M., Hutchinson, S.L. \& Brunsell, N.A. (2012) Timing of climate variability and grassland productivity. Proceedings of the National Academy of Sciences of the United States of America, 109, 3401-3405.

Dai, A. (2011) Drought under global warming: A review. Wiley Interdisciplinary Reviews: Climate Change, 2, 45-65. 
Granda, E., Camarero, J.J., Jimeno, T.E., Martínez-Fernández, J. \& Valladares, F. (2013) Intensity and timing of warming and drought differentially affect growth patterns of co-occurring Mediterranean tree species. European Journal of Forest Research, 132, 469-480.

Grissino-Mayer, H.D. \& Fritts, H.C. (1997) The International Tree-Ring Data Bank: an enhanced global database serving the global scientific community. The Holocene, 7, 235-238.

Gutiérrez, E., Campelo, F., Camarero, J.J., Ribas, M., Muntán, E., Nabais, C. \& Freitas, H. (2011) Climate controls act at different scales on the seasonal pattern of Quercus ilex L. stem radial increments in NE Spain. Trees - Structure and Function, 25, 637-646.

Hair, J.F., Anderson, R.E., Tatham, R.L. \& Black, W.C. (1998) Multivariate data analysis. Prentice Hall, New York, New York, USA.

Harris, I., Jones, P.D., Osborn, T.J., \& Lister, D.H. (2013) Updated high-resolution grids of monthly climatic observations. International Journal of Climatology. Doi: 10.1002/joc. 3711

Hayes, M., Svoboda, M., Wall, N. \& Widhalm, M. (2011) The Lincoln Declaration on Drought Indices: Universal Meteorological Drought Index recommended. Bulletin of the American Meteorological Society, 92, 485-488.

Huberty, C.J. (1994) Applied discriminant analysis. Wiley, New York, USA.

Johnson, D.M., McCulloh, K.A., Woodruff, D.R. \& Meinzer, F.C. (2012) Hydraulic safety margins and embolism reversal in stems and leaves: why are conifers and angiosperms so different? Plant Science, 195, 48-53.

Kursar, T.A., Engelbrecht, B.M.J., Burke, A., Tyree, M.T., El Omari, B. \& Giraldo, J.P. (2009) Tolerance to low leaf water status of tropical tree seedlings is related to drought performance and distribution. Functional Ecology, 23, 93-102. 
Linares, J.C., Camarero, J.J. \& Carreira, J.A. (2010). Competition modulates the adaptation capacity of forests to climatic stress: insights from recent growth decline and death in relict stands of the Mediterranean fir Abies pinsapo. Journal of Ecology, 98, 592-603.

Maherali H., Pockman W.T. \& Jackson R.B. (2004) Adaptive variation in the vulnerability of woody plants to xylem cavitation. Ecology, 85, 2184-2199.

McDowell, N., Pockman, W.T., Allen, C.D., Breshears, D.D., Cobb, N., Kolb, T., Plaut, J., Sperry, J., West, A., Williams, D.G. \& Yepez, E.A. (2008) Mechanisms of plant survival and mortality during drought: why do some plants survive while others succumb to drought? New Phytologist, 178, 719-739.

McKee, T.B.N., Doesken, J., Kleist, J. (1993) The relationship of drought frecuency and duration to time scales. Eight Conf. On Applied Climatology. Anaheim, CA, Amer. Meteor. Soc. 179184.

Nemani, R.R., Keeling, C.D., Hashimoto, H., Jolly, W.M., Piper, S.C., Tucker, C.J., Myneni, R.B. \& Running, S.W. (2003) Climate-driven increases in global terrestrial net primary production from 1982 to 1999. Science, 300, 1560-1563

Orwig, D.A. \& Abrams, M.D. (1997) Variation in radial growth responses to drought among species, site, and canopy strata. Trees: Structure and Function, 11, 474-484.

Palmer, W.C. (1965) Meteorological droughts. U.S. Department of Commerce Weather Bureau Research Paper 45, 58 pp.

Pasho, E., Camarero JJ, de Luis, M. \& Vicente-Serrano, S.M. (2011) Impacts of drought at different time scales on forest growth across a wide climatic gradient in north-eastern Spain. Agricultural and Forest Meteorology, 151, 1800-1811.

Payette, S. \& Delwaide, A. (2004) Dynamics of subarctic wetland forests over the past 1500 years. Ecological Monographs, 74, 373-391. 
Peng, C., Ma, Z., Lei, X., Zhu, Q., Chen, H., Wang, W., Liu, S., Li, W., Fang, X. \& Zhou, X. (2011) A drought-induced pervasive increase in tree mortality across Canada's boreal forests. Nature Climate Change, 9, 467-471.

Pockman, W.T. \& Sperry, J.S. (2000) Vulnerability to xylem cavitation and the distribution of sonoran desert vegetation. American Journal of Botany, 87, 1287-1299.

Richman, M. B. (1986) Rotation of principal components. Journal of Climatology, 6, 29- 35.

Rouse, J.W., Haas, R.H., Schell, J.A., Deering, D.W. (1974) Monitoring the vernal advancement and retrogradation (green wave effect) of natural vegetation. NASA/GSFC type III Final Report, Greenbelt, MD.

Stokes, M.A. \& Smiley, T.L. (1968) An introduction to tree ring dating. The University of Chicago Press, Chicago.

Trenberth, K.E., Dai, A., van der Schrier, G., Jones, P.D., Barichivich, J., Briffa, K.R., Sheffield, J. (2014) Global warming and changes in drought. Nature Climate Change, 4, 17-22.

Tucker, C.J., Pinzon, J.E., Brown, M.E., Slayback, D.A., Pak, E.W., Mahoney, R., Vermote, E.F. \& Saleous, N.E. (2005) An Extended AVHRR 8-km NDVI Data Set Compatible with MODIS and SPOT Vegetation NDVI Data. International Journal of Remote Sensing, 26, 4485-5598.

Vicente-Serrano, S.M., Beguería, S. \& López-Moreno, J.I. (2010) A Multi-scalar drought index sensitive to global warming: The Standardized Precipitation Evapotranspiration Index SPEI. Journal of Climate, 23, 1696-1718.

Vicente-Serrano, S.M., Gouveia, C., Camarero, J.J., Beguería, S., Trigo, R., López-Moreno, J.I., Azorín-Molina, C., Pasho, E., Lorenzo-Lacruz, J., Revuelto, J., Morán-Tejeda, E. \& Sanchez-Lorenzo, A. (2013) The response of vegetation to drought time-scales across global land biomes. Proceedings of the National Academy of Sciences of the United States of America, 110, 52-57. 
Williams, A.P., Allen, C.D., Macalady, A.K., Griffin, D., Woodhouse, C.A., Meko, D.M., Swetnam, T.W., Rauscher, S.A., Seager, R., Grissino-Mayer, H.D., Dean, J.S., Cook, E.R., Gangodagamage, C., Cai, M. \& McDowell, N.G. (2013) Temperature as a potent driver of regional forest drought stress and tree mortality. Nature Climate Change, 3, 292-297.

Wu, X., Liu, H., Guo, D., Anenkhonov, O.A., Badmaeva, N.K. \& Sandanov, D.V. (2012) Growth decline linked to warming-induced water limitation in hemi-boreal forests. PLoS ONE, 7, e42619. doi:10.1371/journal.pone.0042619 


\section{Figures}
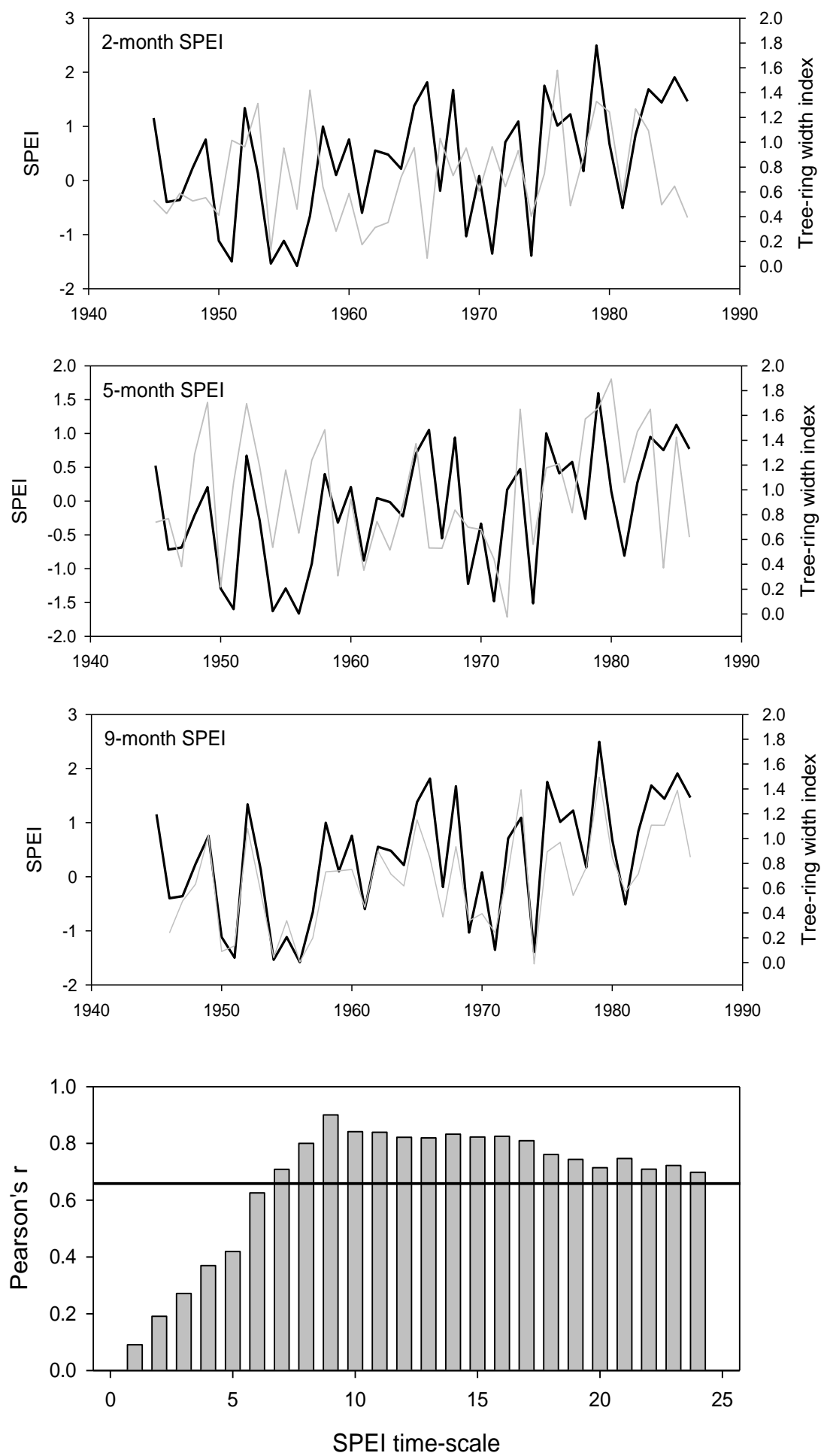

Figure 1. Example of the analyses used to relate residual tree-ring width indices (black lines) with detrended SPEI (Mimbres Junction Recollection forest, USA, latitude $33^{\circ} \mathrm{N}$, longitude $108^{\circ} \mathrm{W}$ ). The presented SPEI series (grey lines) correspond to 2-, 5- and 9-month long series calculated for May. The lowermost figure shows the Pearson correlation coefficients (bars) calculated between the May SPEI and the tree-ring chronology for time scales ranging from 1 to 24 months (the horizontal line indicates the 0.05 significance level of the Pearson correlation). 

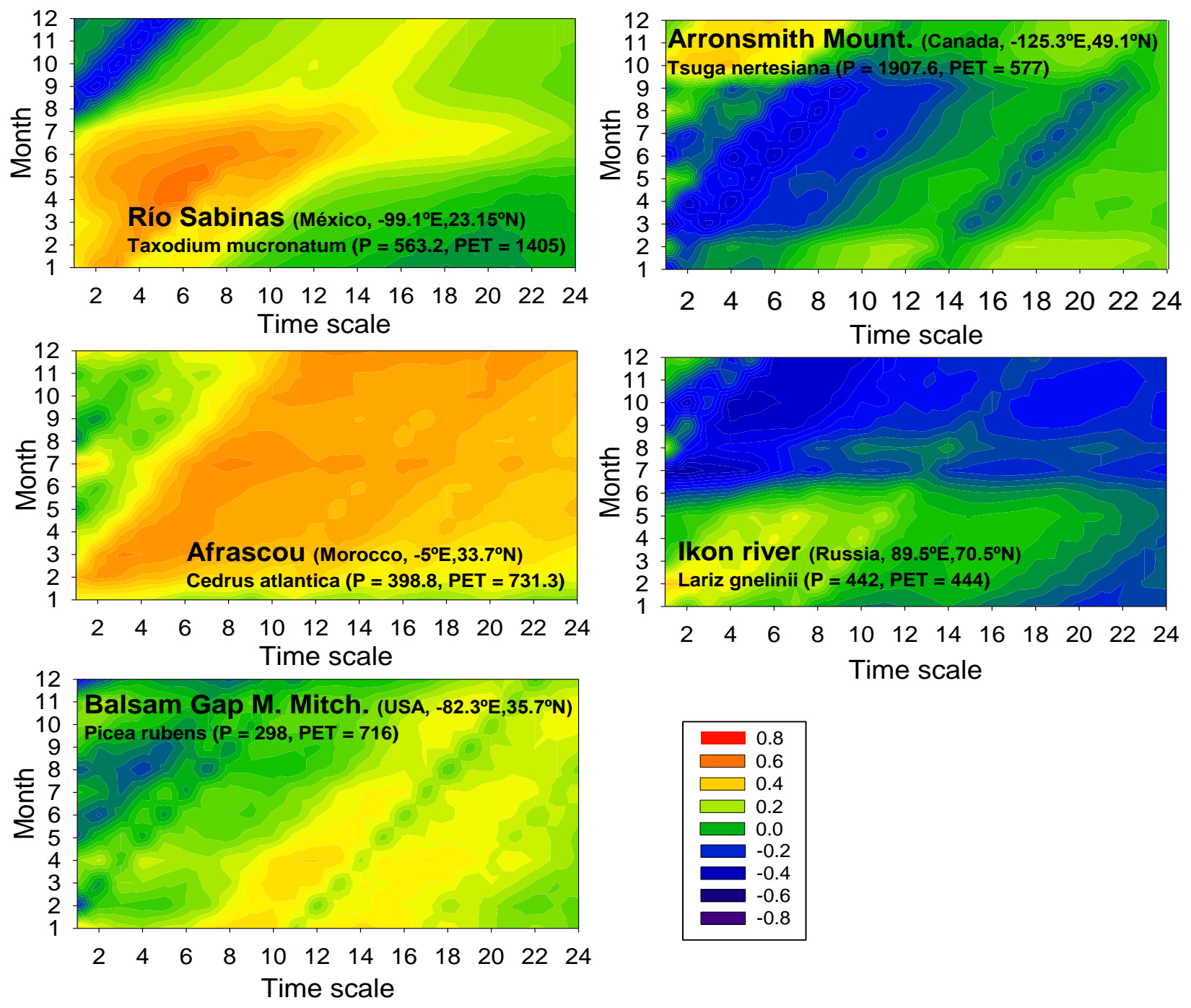

Figure 2. Correlation coefficients (lower color scale) calculated between tree-ring width and SPEI series of each month ( $y$ axis) at 1- to 24-month long scales ( $x$ axis) in five forests with contrasting climatic conditions: three arid sites (Río Sabinas, Afrascou and Balsam Gap M. Mitch) in which average annual potential evapotranspiration (PET) is higher than average annual precipitation; one humid forest (Arronsmith Mountain) in which average annual precipitation is much higher than annual PET; and one boreal forest (Ikon river) with low and similar annual precipitation and PET values. 

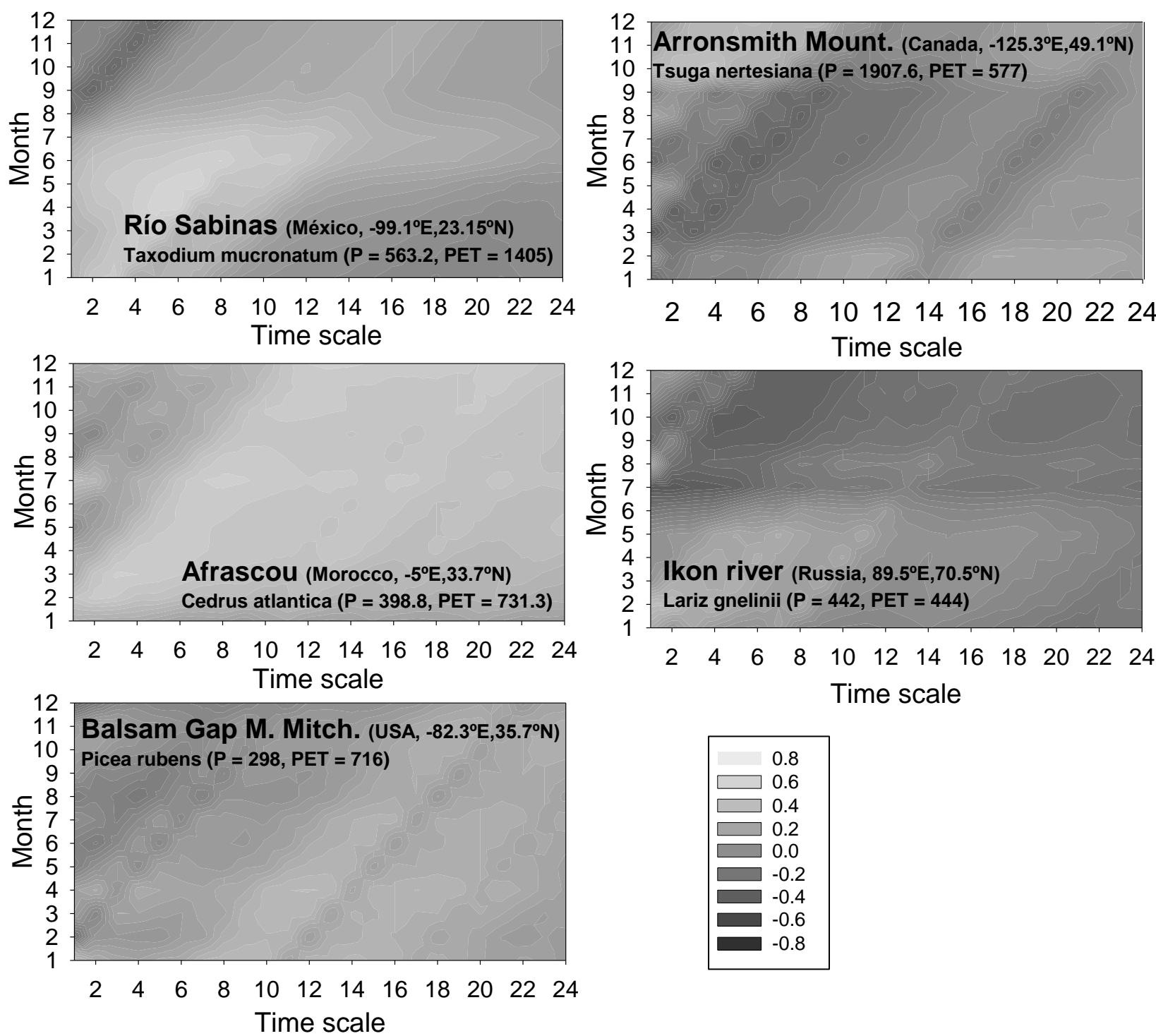

Figure $2(\mathbf{b} / \mathbf{w})$. Correlation coefficients (lower grey scale) calculated between tree-ring width and SPEI series of each month ( $y$ axis) at 1- to 24-month long scales ( $x$ axis) in five forests with contrasting climatic conditions: three arid sites (Río Sabinas, Afrascou and Balsam Gap M. Mitch) in which average annual potential evapotranspiration (PET) is higher than average annual precipitation; one humid forest (Arronsmith Mountain) in which average annual precipitation is much higher than annual PET; and one boreal forest (Ikon river) with low and similar annual precipitation and PET values. 

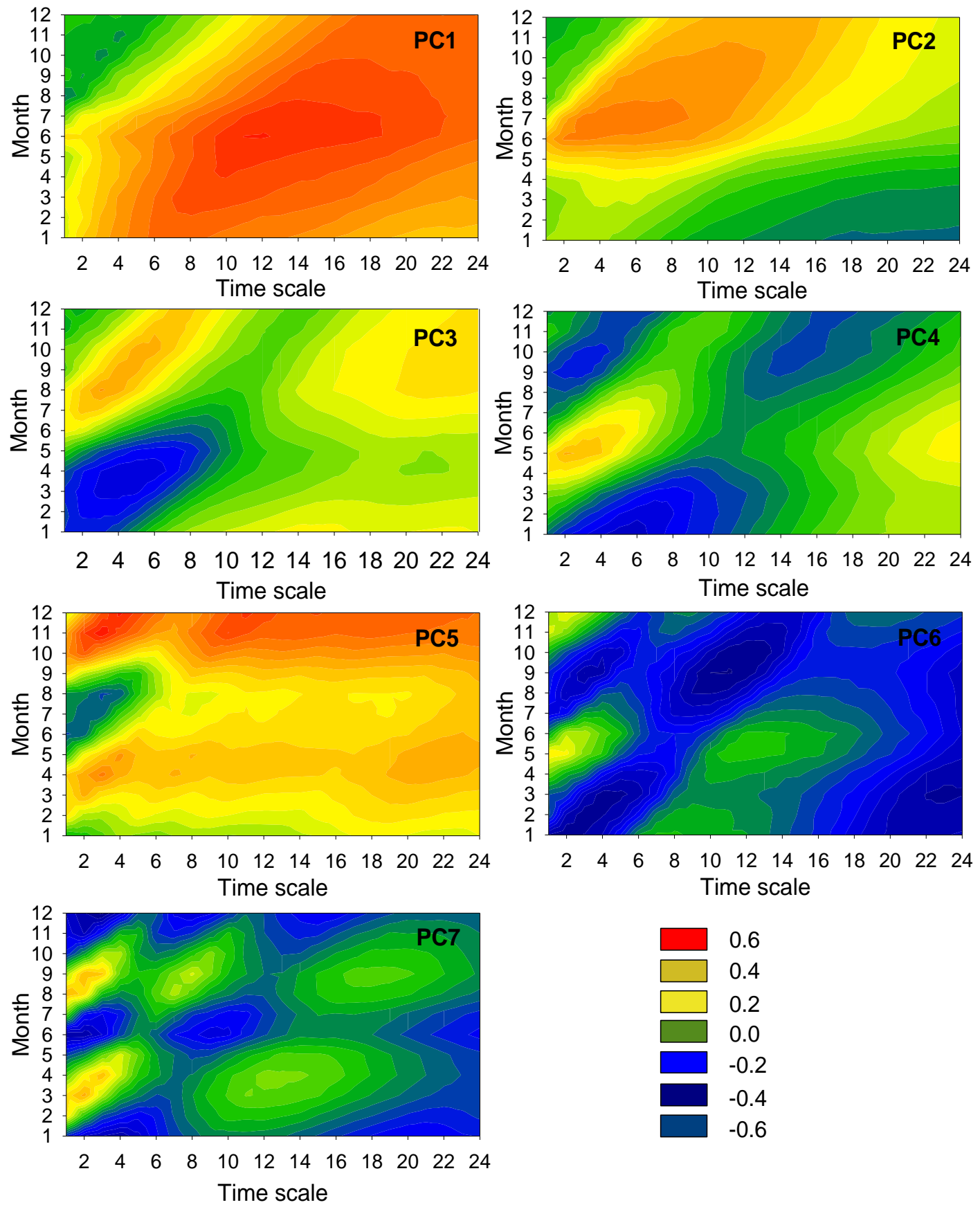

Figure 3. Major modes of tree growth responses to 1- to 24-month long SPEI time-scales based on the first seven principal components (PCs) of a Principal Component Analysis. The PCs are shown in the original variables (Pearson correlation coefficients, lower color scale) to improve the interpretation of the results. 

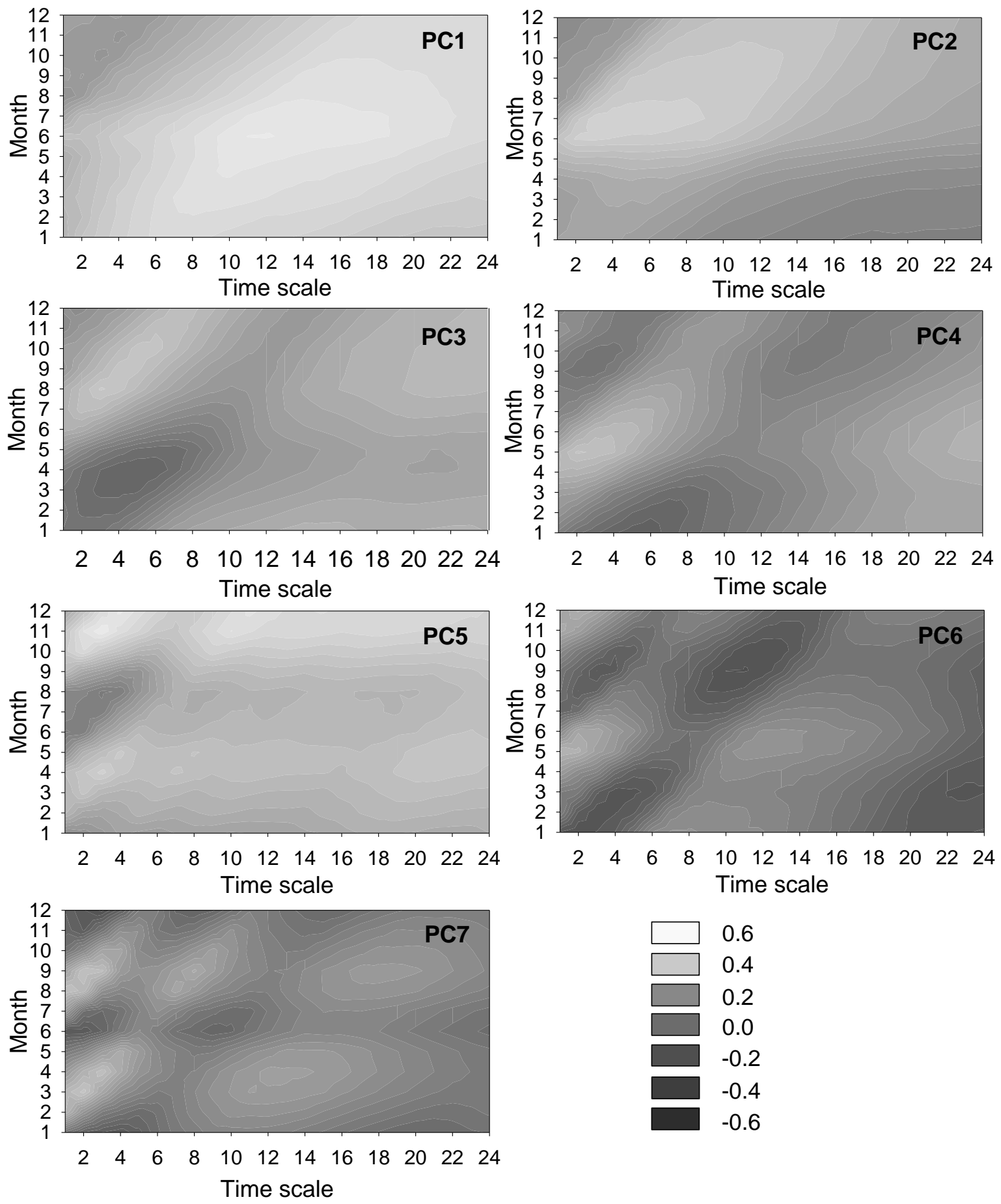

Figure $3(\mathbf{b} / \mathbf{w})$. Major modes of tree growth responses to 1- to 24-month long SPEI time-scales based on the first seven principal components (PCs) of a Principal Component Analysis. The PCs are shown in the original variables (Pearson correlation coefficients, lower grey scale) to improve the interpretation of the results. 
(a)
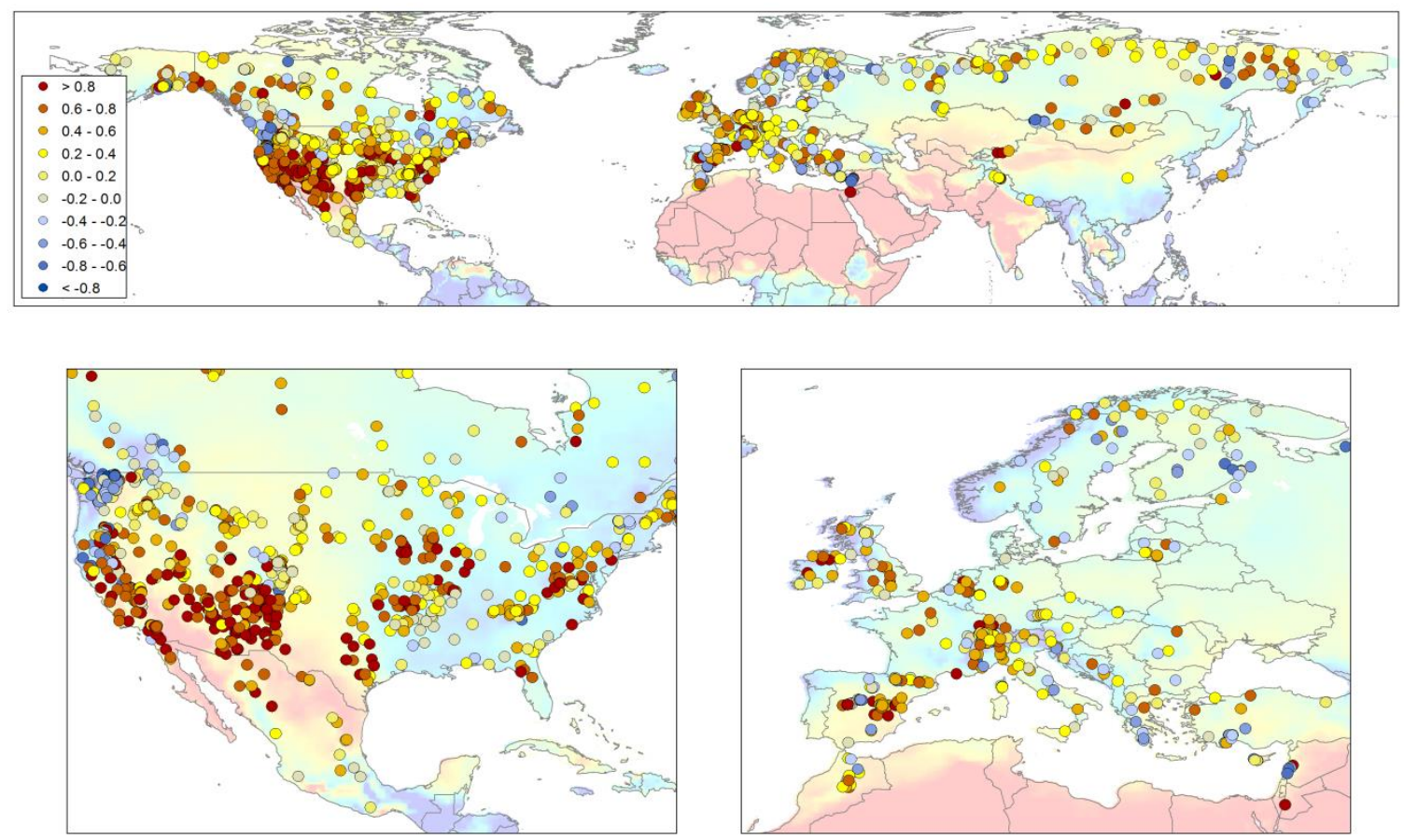

(b)
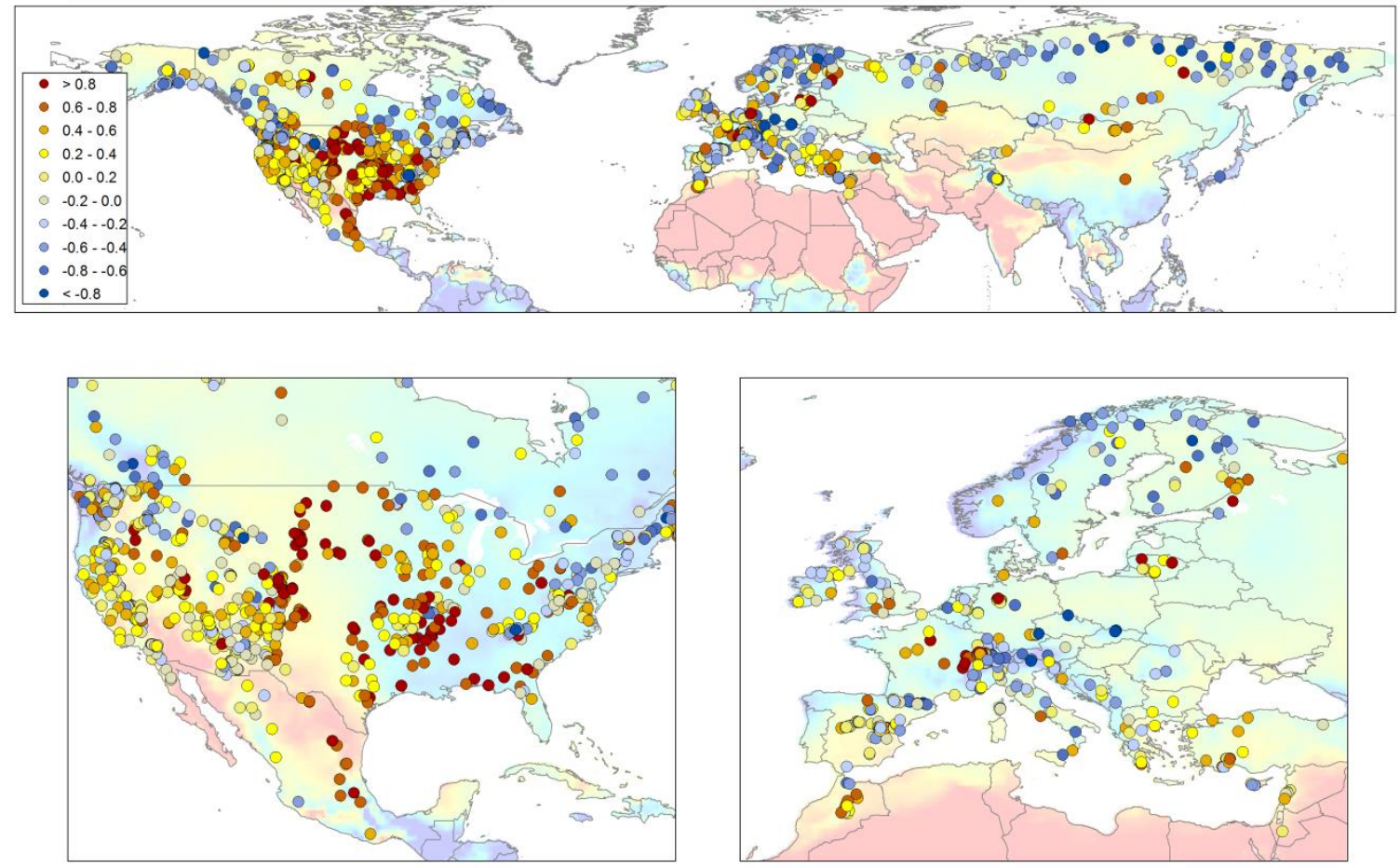

Figure 4. Spatial distribution of the loadings of the first (a) and second (b) principal components (colored points) of the Principal Component Analysis summarizing the responses of tree-ring width series to SPEI at global and regional (North America, Europe) scales. The background color scale indicates areas with negative (red) and positive (blue) water balances, respectively. 
(a)
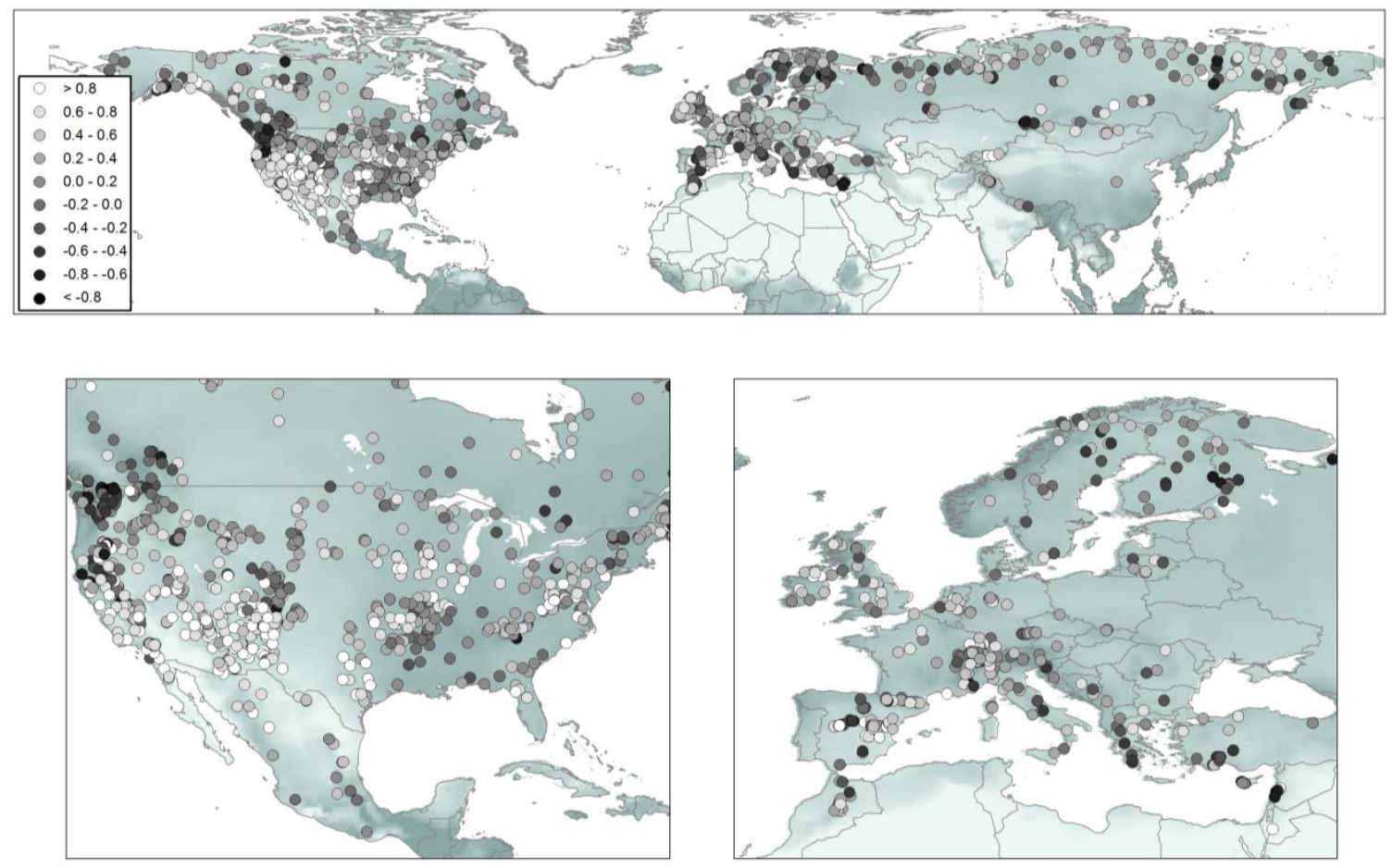

(b)
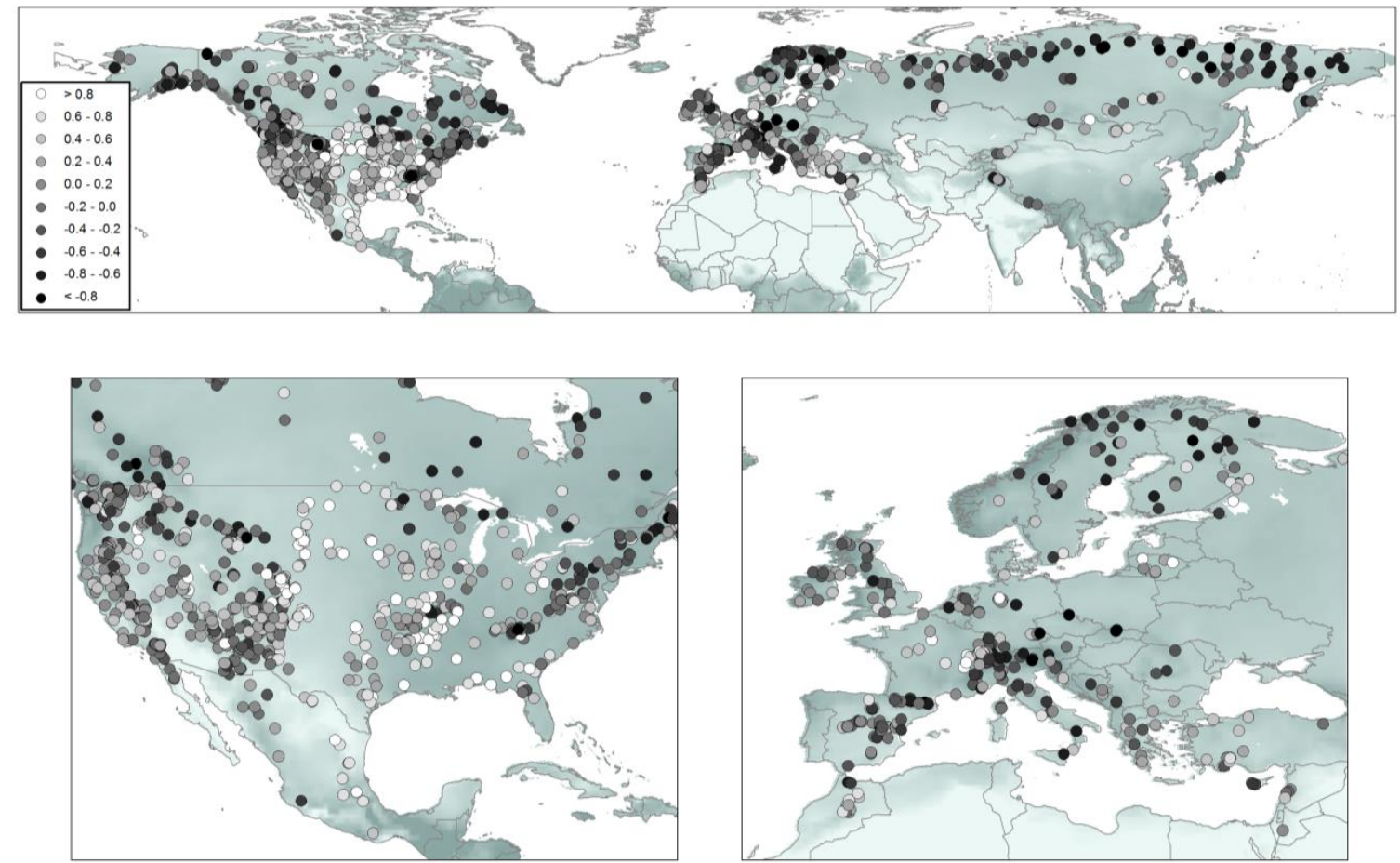

Figure $4(\mathbf{b} / \mathbf{w})$. Spatial distribution of the loadings of the first (a) and second (b) principal components (grey points) of the Principal Component Analysis summarizing the responses of tree-ring width series to SPEI at global and regional (North America, Europe) scales. The background scale indicates areas with negative (light grey) and positive (dark grey) water balances, respectively. 

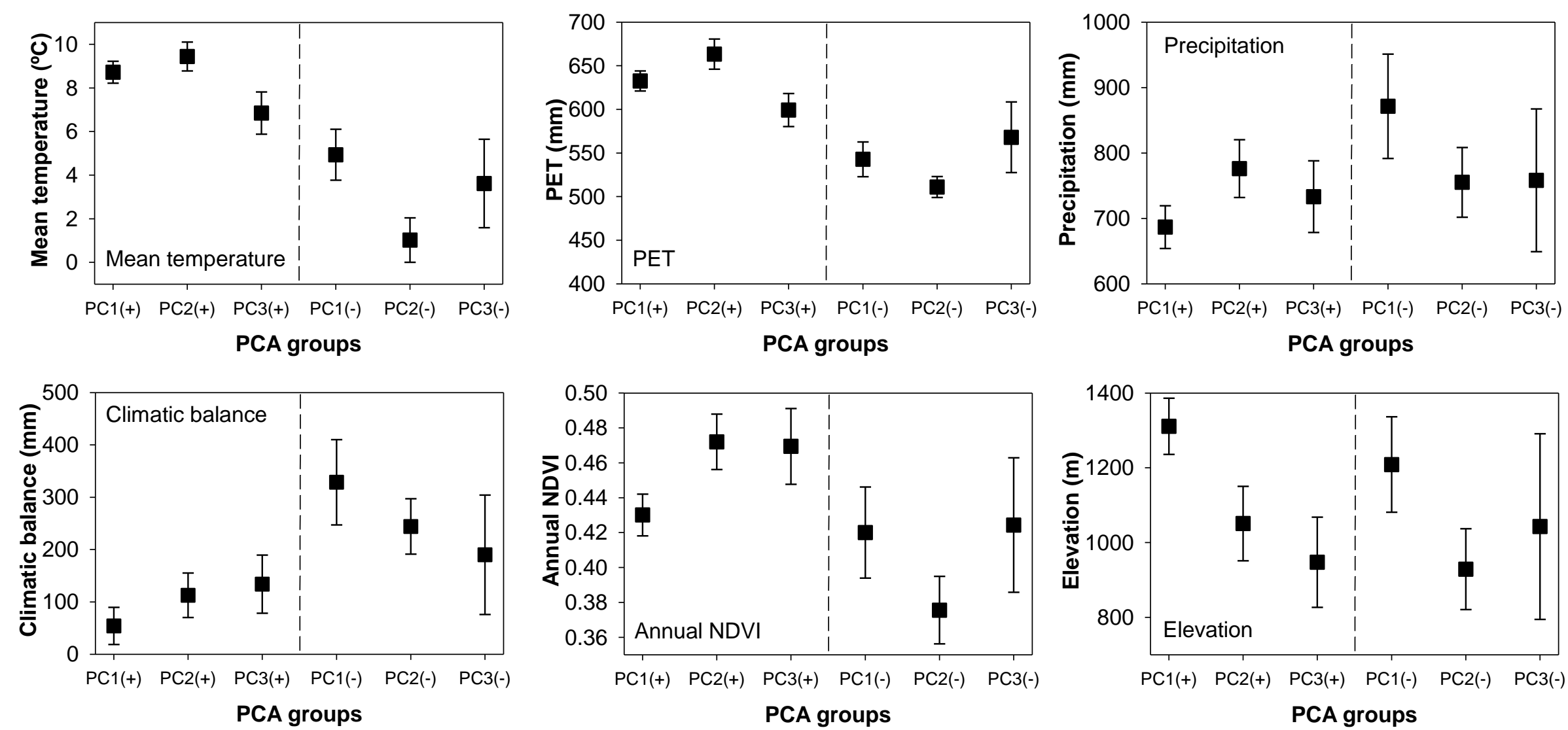

Figure 5. Mean values of the main variables (annual mean temperature, potential evapotranspiration -PET-, precipitation, climatic water balance, annual NDVI and elevation) characterized by the first three principal components (PC1, PC2 and PC3; their effects are indicated between parentheses) of the tree-ring width responses to SPEI time-scales obtained in a Principal Component Analysis. Error bars indicate two standard errors of the average. 

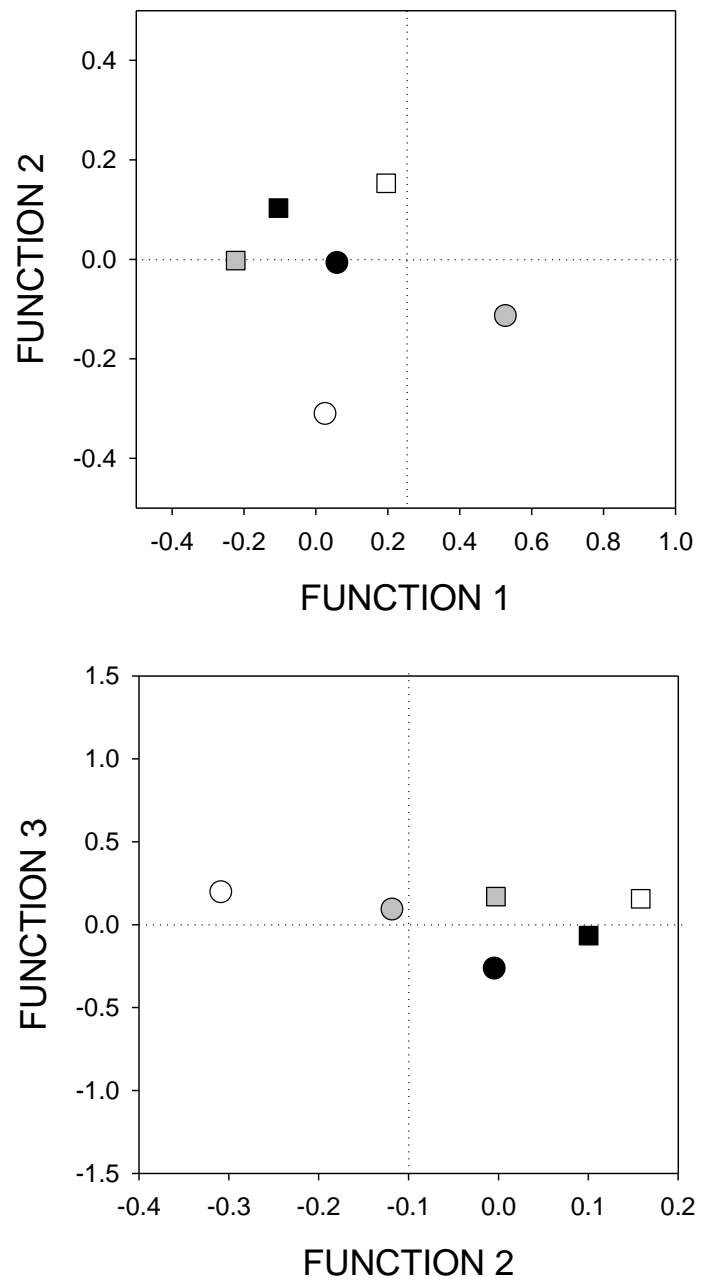

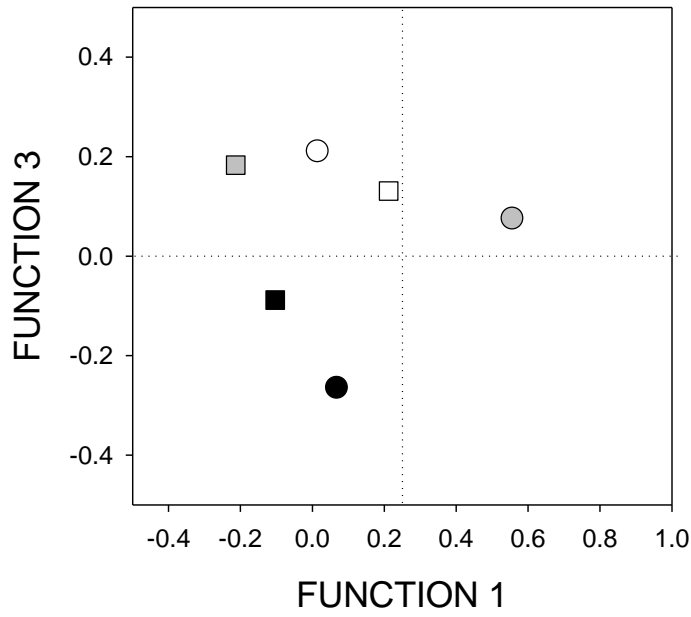

$\square \mathrm{PC} 2(+) \quad \bigcirc \mathrm{PC} 2(-)$

$\square$ PC3(+) $\bigcirc$ PC3(-)

Figure 6. Centroids of the groups obtained through a Principal Component Analysis (effects are indicated between parentheses) corresponding to the first three functions of the predictive discriminant analysis (PDA). 


\section{Tables}

\begin{tabular}{|c|cc|cc|}
\hline & \multicolumn{2}{|c|}{ Phylogeny } & \multicolumn{2}{c|}{ Leaf phenology } \\
\hline Group (effect) & Angiosperm & Gymnosperm & Deciduous & Evergreen \\
\hline PC1 (+) & 17.7 & 82.3 & 21.3 & 78.7 \\
PC2 (+) & 29.9 & 70.1 & 37.2 & 62.8 \\
PC3 (+) & 10.3 & 89.7 & 12.2 & 87.8 \\
PC1 (-) & 8.2 & 91.8 & 19.7 & 80.3 \\
PC2 (-) & 5.1 & 94.9 & 27.0 & 73.0 \\
PC3 (-) & 8.3 & 91.7 & 30.0 & 70.0 \\
Total (\%) & 16.6 & 83.4 & 24.6 & 75.4 \\
\hline
\end{tabular}

Table 1. Percentage of forest types based on the tree phylogeny and leaf phenology considering the first three principal components of a PCA (PC1, PC2, PC3) summarizing the growth responses to the SPEI drought index. The PCs' effects are indicated between parenthesis. 


\begin{tabular}{|l|c|c|c|}
\hline & \multicolumn{3}{|c|}{ PDA functions (variance in \%) } \\
\hline \multicolumn{1}{|c|}{ Variables } & PDA1 (37.6) & PDA2 (18.1) & PDA3 (14.2) \\
\hline Annual Temperature & $-0.478^{*}$ & 0.139 & -0.026 \\
\hline Temperature DJF & $-0.584^{*}$ & -0.091 & 0.096 \\
\hline Temperature MAM & $-0.478^{*}$ & 0.083 & 0.011 \\
\hline Temperature JJA & -0.026 & $0.487^{*}$ & -0.251 \\
\hline Temperature SON & $-0.464^{*}$ & 0.185 & -0.044 \\
\hline Annual PET & -0.105 & 0.338 & -0.126 \\
\hline PET DJF & $-0.468^{*}$ & -0.417 & 0.339 \\
\hline PET MAM & -0.346 & 0.039 & 0.006 \\
\hline PET JJA & 0.351 & $0.495^{*}$ & -0.244 \\
\hline PET SON & $-0.465^{*}$ & 0.127 & -0.035 \\
\hline Annual precipitation & -0.038 & -0.089 & 0.365 \\
\hline Precipitation DJF & -0.064 & -0.145 & -0.098 \\
\hline Precipitation MAM & -0.210 & 0.001 & 0.325 \\
\hline Precipitation JJA & 0.043 & -0.061 & $0.685^{*}$ \\
\hline Precipitation SON & 0.080 & -0.094 & $0.367^{*}$ \\
\hline Annual water balance & -0.002 & -0.194 & 0.386 \\
\hline Water balance DJF & 0.201 & 0.100 & -0.275 \\
\hline Water balance MAM & -0.055 & -0.018 & 0.324 \\
\hline Water balance JJA & -0.164 & -0.316 & $0.610^{*}$ \\
\hline Water balance SON & 0.259 & -0.141 & $0.371^{*}$ \\
\hline Annual NDVI & -0.235 & 0.052 & 0.217 \\
\hline NDVI DJF & -0.420 & -0.155 & 0.241 \\
\hline NDVI MAM & -0.324 & -0.002 & 0.153 \\
\hline NDVI JJA & 0.237 & 0.300 & 0.127 \\
\hline NDVI SON & -0.283 & 0.049 & 0.215 \\
\hline Latitude & $0.673^{*}$ & 0.370 & -0.281 \\
\hline Elevation & -0.330 & 0.232 & -0.105 \\
\hline Terrain curvature & 0.089 & 0.098 & 0.171 \\
\hline Slope & -0.219 & -0.174 & 0.111 \\
\hline Solar radiation & -0.088 & -0.187 & 0.021 \\
\hline
\end{tabular}

Table 2. Structure matrix of the first three components (the variance explained by each component is indicated between parenthesis) of the predictive discriminant analysis (PDA). The table shows the correlation values of each predictor variable with the three discriminant functions. Variables' abbreviations are: DJF, winter (December, January, February); MAM, spring (March, April, May); JJA, summer (June, July, August); SON, autumn (September, October, November); NDVI, Normalized Difference Vegetation Index; PET, Potential Evapotranspiration. The variables represented in each of the first two functions are marked with asterisks. 